sacros aptos para el consumo del ambiente clerical que rodeaba al pintor, aunándose el gusto clasicista y cierta devoción.

Para concluir con el contenido de sus últimas voluntades, resta señalar que encomendó a sus albaceas, el propio Quintanilla y su mayordomo, Manuel García de Vida, el cobro de atrasos de una pensión que tiene á su fauor reseruada por autoridad Apostólica a cargo de una canonjía en la Catedral de Orihuela, que disfrutaba el Señor Dotor Juan Rodemus (sic). Anualmente debía recibir 80 escudos en moneda romana, aunque no se aclara desde cuándo, de los que sólo había alcanzado a cobrar una partida de 60 . Estos ingresos eran los propios de buena parte de la «población flotante» de religiosos españoles desplazados a Roma: beneficios eclesiásticos, obtenidos por concesión de la curia romana o el mismo Papa, con los que muchos se sustentaban ${ }^{21}$.

Plenamente inmerso en su grupo social, sirviéndose de sus prebendas, su dedicación a la pintura le proporcionó una posición especial en su ámbito, asegurándose en cierto modo una clientela «romanizada». De hecho su pintura sólo es explicable en el contexto romano, a la sombra de Viviano Codazzi, con el que hubo de aprender diestramente las convenciones del género; aunque aun no dispongamos de pruebas documentales de su relación ${ }^{22}$. La calidad de su obra y su posición social, harían de él un referente entre los artistas españoles en la Ciudad de los Papas. De ahí que los pintores que pretendían formar la Academia Española en Roma optaran por el aval del eclesiástico artista, que prestigiaría su petición. Sin embargo, pese a ello y al amparo del culto y poderoso marqués del Carpio, la elusiva respuesta del Consejo de Italia a su petición (que el Marqués procure desembarazarse de esta instancia, respondiendo gratamente a los pintores sin desalentarlos en la forma que juzgare más conveniente, pues el erario no está hoy para semejantes desperdicios) ${ }^{23}$ acabó por frustrar sus aspiraciones. Que Giner falleciera apenas un año después de su solicitud, debió precipitar aun más el final de la «Academia nonata», pues no hay indicios de insistencia en aspirar al patrocinio regio.

Ángel Aterido FernÁNDEZ

\title{
UNA NUEVA TABLA MALLORQUINA DE RAFEL MÒGER
}

El taller pictórico de Rafel Mòger fue con mucho, a juzgar por la tablajería que se ha conservado, el más notable que existió en la ciudad de Palma de Mallorca en el tercer cuarto del siglo Xv.

Lentamente se ha llegado a constituir el catálogo de sus pinturas religiosas y un relativo dossier documental de las religiosas y profanas, realizadas, perdidas y recuperadas a partir del tajo que abrieron los eruditos socios de la Arqueología Luliana, que se pusieron a trabajar a fines del siglo pasado, y, sobre todo, del maestro Chandler Rathfon Post que comenzó a recoger los frutos en su Historia de la Pintura hacia el año $1930^{\prime}$.

\footnotetext{
${ }^{21}$ Antonio Mestre (dir.), Historia de la Iglesia en España. IV La Iglesia en la España de los siglos xVII y xVIII, Madrid, BAC, 1979, p. 38.

${ }^{22}$ Soria, op. cit. Alfonso E. Pérez Sánchez, Pintura barroca en España. 1600-1750, Madrid, 1992, p. 392. Recientemente se ha confeccionado un catálogo de la obra de Giner, dentro de la monografía dedicada a los Codazzi (Marshall, op. cit., pp. 505-518), partiendo del material recogido por Soria. No aporta nuevas obras firmadas, basando todas sus conclusiones en arriesgadas y supuestas afinidades estilísticas.

${ }^{23}$ Viñaza, op. cit, p. 272.

1 La bibliografía está reunida básicamente en mi estudio: La pintura medieval mallorquina, su entorno cultural y su iconografía, 4 vols., Palma de Mallorca 1977-1980 (cit. PMM I-IV). Cfr. PMM I, pp. 77-83; III, pp. 111-127 y IV, pp. $162-172$.
} 
Últimamente ha aparecido una nueva tabla, inédita, que testimonia no sólo la maestría del viejo pintor de la saga de los Mòger, que cubre en la isla todo el siglo xv, sino que nos devuelve la perdida esperanza de poder todavía contar con inesperadas pinturas góticas no sólo de fuera de la isla, como resultado del comercio de entresiglos (XIX-XX), sino incluso procedentes de desvanes olvidados o capillas rústicas de fincas del interior de la isla mediterránea.

Este es el caso de la nueva tabla representando a San Vicente Ferrer, el famoso predicador dominico valenciano del siglo $\mathrm{xv}$, que se guarda en la capilla de un predio próximo a la ciudad de Palma, propiedad actualmente de la familia Sastre-Alzamora ${ }^{2}$.

Hacía años que la visita a la pieza estaba proyectada aunque las circunstancias no permitieron cumplir con la agenda y la palabra dada hasta fecha reciente. Así, por fin, se realizó la ilusión de contar no sólo con una pieza más del taller de Rafel Mòger, sino también opinar que éste debe ser el primer vestigio existente del culto isleño a San Vicente Ferrer, O.P. (Valencia, 1350-Vannes, 1419).

Lorenzo Pérez Martínez recogió hace años los datos suficientes para contextualizar la pieza tanto desde el punto de vista sacro como social ${ }^{3}$. En efecto, al estudiar la venida del predicador a Mallorca (a primeros de septiembre de 1413, su campaña de predicación en la ciudad y villas y partida el 22 de enero de 1414) en la documentación conventual del convento de Santo Domingo de Palma, hizo resaltar dos puntos: primero, que la memoria y culto del santo en un principio se concentraron en el único convento dominicano existente. Allí, a raíz de la canonización proclamada en Roma por su compatriota y devoto Calixto III y festejada localmente por el obispo Juan García, O.P., amigo y compañero del santo, en 1456 se empezó una capilla nueva y en 1458 y 1459 ya actuaba una cofradía fundada en honor del nuevo santo.

El segundo punto que queda claro en el trabajo de Lorenzo Pérez es que, a lo largo del siglo XVII la devoción embrionaria se desarrolló súbitamente y dio lugar a una explosión popular no sólo manifiesta en el culto (proclamación de patrón menor de Mallorca en 1675-1676 por Urbano VIII; dedicación de capilla en la catedral entre 1682 y 1686), sino también en la proliferación de leyendas y tradiciones locales y en la multiplicación de capillitas y callejeros.

La consecuencia que deriva inmediatamente de estas premisas es la siguiente: estamos probablemente ante la primera representación de la devoción local al santo predicador, es decir, ante la tabla primitiva de la capilla de Santo Domingo de Palma que, con el tiempo, debió ser sustituida por la imaginería barroca y que vino a parar a manos particulares antes o después de la destrucción del gran templo en aras de la desamortización de Mendizábal. Éste fue el caso de otros varios retablos del actual Museo de Mallorca, como el llamado de San Bernardo (de la capilla de los Oleza), el de la Virgen de Gracia y el de la Virgen del Santo Novicio, pergeñada esta última asimismo por Rafel Mòger.

La tabla mide actualmente $88 \mathrm{~cm} . \times 191 \mathrm{~cm}$. y el falso marco que la encuadra ha mordido en su parte superior izquierda la pintura dejando despuntada la almendra con el Cristo de Piedad y su corte de ángeles, armados con los improperios de la Pasión.

Al separar la tabla de su primigenia mazonería hubo que protegerla y adecentarla con el enmarcado actual. Realmente, la tabla no ha padecido mucho y, aunque lleva repintes, permite hacerse cargo de la figura del santo varón de pie en hábito de la Orden y sin tocado. La gran capa negra encaja muy bien el cuerpo en el campo, levantada por el brazo derecho que apunta al Cristo del Juicio, y por el izquierdo, que también arreboza la capa, mostrando el libro de la escritura sacra con el texto clásico en la iconografía del santo, también alusivo al Juicio divino: Timete Dominum et date illi honorem quia venit hora iudicii eius. Apocalipsis quarto decimo.

\footnotetext{
2 Debo agradecer a la misma, en especial a doña Magdalena Alzamora, las facilidades dadas para examinar y fotografiar la pieza.

3 L. Pérez, «Devoción de la ciudad de Palma a San Vicente Ferrer», Studia 25 (1955) 3-16 (de la separata).
} 


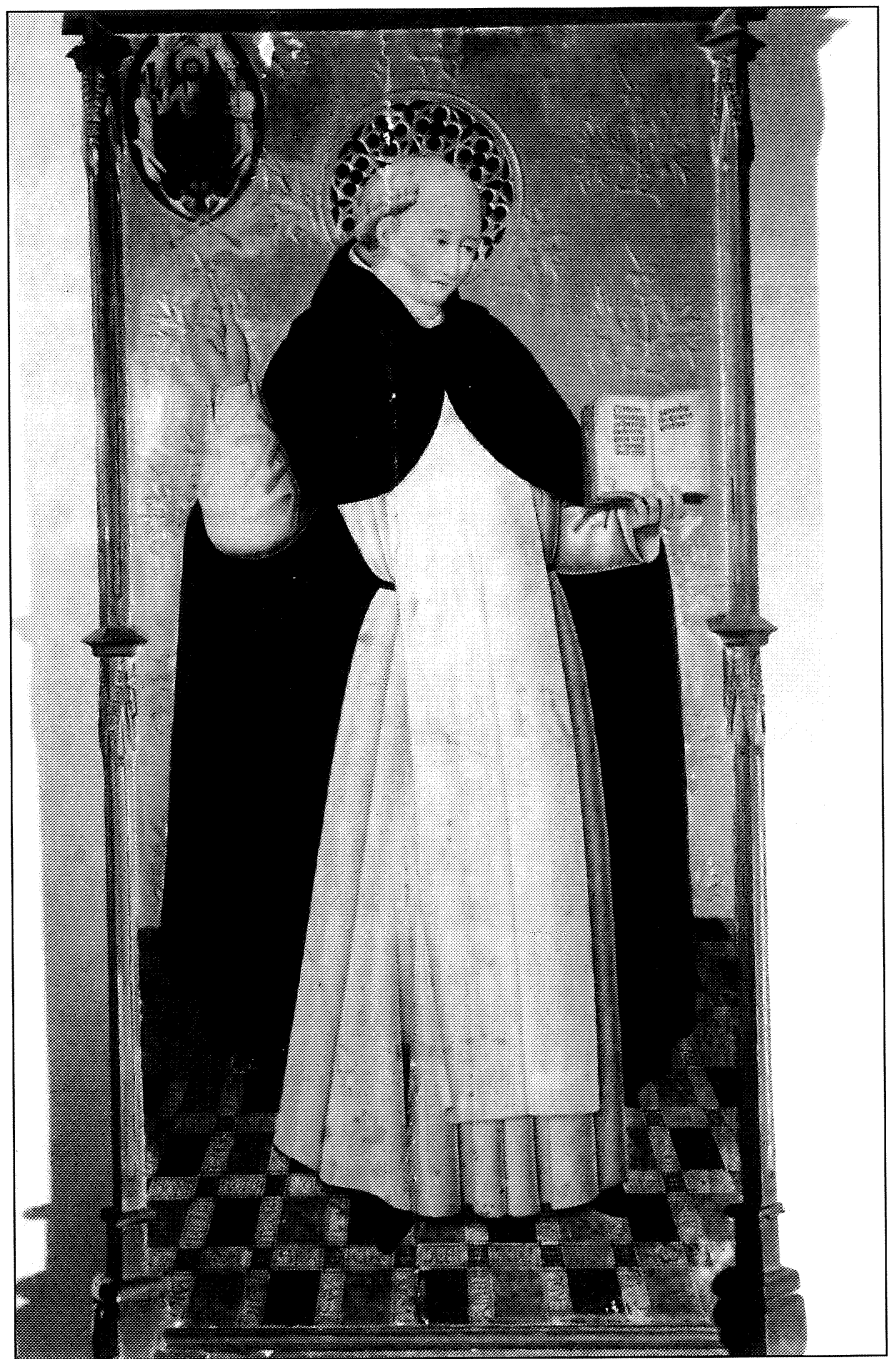

Rafel Mòger: Tabla de San Vicente Ferrer: Palma de Mallorca.Colección particular. (Foto Jaume Gual).

El esquema compositivo sigue el mismo modelo que el San Bernardino de Siena del retablo de Alcudia del mismo autor, si bien aquí el Cristo en la almendra mística sustituye al Nombre de Jesús dentro del sol radiante ${ }^{4}$.

El pavimento de azulejos valencianos empedra un damero de negros y cárdenos, con una abigarrada serie de letreros extraídos de las dos oraciones clásicas de la catequesis medieval: Pater noster y el Ave Maria.

Por encima del mismo, el fondo es de oro y reproduce los gofrados en grueso relieve propios de su taller, bien destacados y separados unos de otros, pertenecientes no al modelo simple de dos ramas, sino al más complejo de cuatro ramas por tallo de planta.

La aureola, decorada con un módulo de cruz alveolada, con el fondo negro, juega armoniosamente con el negro de la capa y da un toque de elegancia al conjunto al centrar la atención sobre la testa del santo.

${ }^{4}$ Cfr. la reproducción en color en G. Llompart, La pintura gótica en Mallorca, Palma, Ajuntament; 1987, fig. 63, es el número 99 del catálogo (PMM III). 
Las acanaladuras del faldón del hábito siguen las tiradas de la Virgen de la Merced de Selva, documentada en 1479, aunque para mí son ciertos rasgos de la cara, como la nariz rectilínea, la boca minúscula y, sobre todo, los ojos — detalle que Post ya subrayaba en Rafel Mòger-, los que aproximan a los santos del retablo de Santa Práxedes del palacio de la Almudaina. Sobre todo el San Vidal caballero, que está orientado en la misma dirección. Este retablo fue encargado en 1459 y Rafel Mòger cobró su finiquito en $1465^{5}$.

Concluyendo, pues, esta primera valoración cabría pensar que la factura de esta tabla de San Vicente Ferrer puede quedar muy próxima a la canonización y, dada la sentencia escolástica, recomienda que nou multiplicentur entia sine necessitate, bien podríamos sugerir que se tratara de la primera imagen que se veneró en la ciudad de Palma a mediados del siglo xv del popular predicador dominico.

P. GABRIEL LlOMPART

\section{¿OTRO TÍTULO DE EL CONCIERTO DE PALMAROLI?}

El cuadro El Concierto (tabla engatillada, $47,5 \times 67,5 \mathrm{~cm}$.) ${ }^{1}$, obra clave del pintor Vicente Palmaroli González (1834-1896; desde 1895 director del Museo del Prado), es generalmente conocido también por otros nombres, como Musica di Camera, Tertulia de confianza, Una reunión galante por los que ha pasado en diversas oportunidades ${ }^{2}$. El cuadro que Reyero relega en su minucioso estudio de la Pintura y escultura en España, $1800-1910^{3}$ a un lugar menos importante, surgió probablemente en 1880, poco antes de ser Palmaroli nombrado, en 1883, director de la Academia Española de Bellas Artes de Roma, cuando ya su nombre adquirió el máximo prestigio tanto en la capital española como fuera, sobre todo en París.

Hoy, aparte de la descripción habitual de la pintura donde dos hombres y una mujer están escuchando a otra dama tocando la mandolina, ya sabemos más acerca del cuadro, sobre todo de la representación del cuadro colgado por encima de la chimenea. Representa a La Virgen rodeada de Santos, de Rubens, según la pintura suya que estuvo primero en El Escorial, y hoy en El Prado. Es un claro principio del cuadro dentro del cuadro. Palmaroli muestra aquí su ejecución virtuosista, gustosa del precionismo y muy depurado dibujo, de gama ausente de tierras y pardos.

Ahora, dentro de mis búsquedas de huellas del arte español del s. XIX en el ambiente checo que ya ha dado primeros frutos ${ }^{4}$, encuentro el cuadro de Palmaroli reproducido, junto con al-

\footnotetext{
${ }^{5}$ Cfr. Llompart, PMM III, núm. 91; IV, p. 166, que debe completarse en G.. Llompart, Miscelánea documental de pintura y picapedrería medieval mallorquina, Palma, 1999 (Trabajos del Museo de Mallorca, núm. 55), doc. núm. 106.

1 Rosa Pérez y Morandeira, Vicente Palmaroli. Madrid, 1971, p. 49, repr. 33 y solapa y lám. I a colores, comentario a las reproducciones. Firmado abajo a la izquierda: V. Palmaroli. Perteneció a la col. Bauer. En 1931 Amutio lo tasó en 3.500 pesetas, y lo compró el hijo del artista, quien a su muerte lo legó al extinto Museo Nacional de Arte Moderno (y Contemporáneo). De este cuadro - advierte la autora-, amorosamente trabajado, hay otra versión reducida, que esta autora califica de anterior, a juzgar por los titubeos de composición (Concierto, de la antigua colección Van Raalte). En uno y otro, la maja concertista reproduce la figura de la Maja de la guitarra de la col. D. Antonio Bilbao (Las Arenas), con distinta modelo y algunas variantes de indumentaria.

${ }^{2}$ Museo del Prado. Casón del Buen Retiro. Catálogo de las pinturas del siglo XIX. Madrid, 1985. Úvod Alfonso E. Pérez Sánchez, kat. ed. Joaquín de la Puente, núm. 4551, p. 189.

${ }^{3}$ Carlos Reyero y Mireia Freixa, Pintura y escultura en España. 1800-1910. Madrid, 1995, p. 165.

4 «Artistas españoles en las exposiciones de la Unidad de Bellas Artes de Praga de 1891 a 1910». Bulletin of the National Gallery in Prague, VII-VIII, 1997-1998, pp. 82-96, il., y Bulletí de la Reial Académia Catalana de Belles Arts de Sant
} 